\title{
Activated carbons prepared from mixtures of coal tar pitch and petroleum pitch and their electrochemical performance as electrode materials for electric double-layer capacitor
}

\author{
Eunji Lee, Soon Hyung Kwon, Poo Reum Choi, Ji Chul Jung^and Myung-Soo Kim^ \\ Department of Chemical Engineering, Myongji University, Yongin 449-728, Korea
}

\section{Article Info \\ Received 24 November 2014 \\ Accepted 9 January 2015 \\ *Corresponding Author \\ E-mail: jcjung@mju.ac.kr myungkim@mju.ac.kr \\ Tel: $+82-31-330-6391$ \\ Open Access \\ DOI: http://dx.doi.org/ \\ 10.5714/CL.2015.16.2.078 \\ This is an Open Access article distributed under the terms of the Creative Commons Attribution Non-Commercial License (http://creativecommons.org/licenses/ by-nc/3.0/) which permits unrestricted non-commercial use, distribution, and reproduction in any medium, provided the original work is properly cited.}

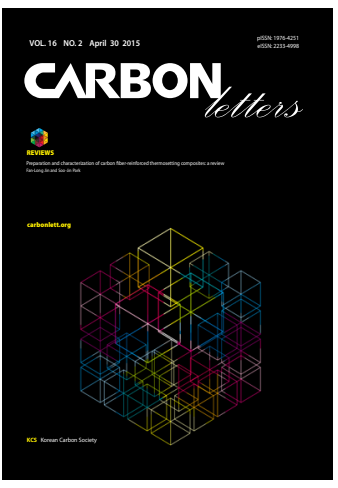

http://carbonlett.org

pISSN: $1976-4251$

elSSN: 2233-4998

Copyright $\odot$ Korean Carbon Society

\begin{abstract}
Activated carbons (ACs) were prepared by activation of coal tar pitch (CTP) in the range of $700^{\circ} \mathrm{C}-1000^{\circ} \mathrm{C}$ for $1-4 \mathrm{~h}$ using potassium hydroxide $(\mathrm{KOH})$ powder as the activation agent. The optimal activation conditions were determined to be a CTP/KOH ratio of 1:4, activation temperature of $900^{\circ} \mathrm{C}$, and activation time of $3 \mathrm{~h}$. The obtained ACs showed increased pore size distribution in the range of 1 to $2 \mathrm{~nm}$ and the highest specific capacitance of $122 \mathrm{~F} / \mathrm{g}$ in a two-electrode system with an organic electrolyte, as measured by a charge-discharge method in the voltage range of $0-2.7 \mathrm{~V}$. In order to improve the performance of the electric double-layer capacitor electrode, various mixtures of CTP and petroleum pitch (PP) were activated at the optimal activation conditions previously determined for CTP. Although the specific capacitance of AC electrodes prepared from CTP only and the mixtures of CTP and PP was not significantly different at a current density of $1 \mathrm{~A} / \mathrm{g}$, the $\mathrm{AC}$ electrodes from CTP and PP mixtures showed outstanding specific capacitance at higher current rates. In particular, CTP-PP61 (6:1 mixture) had the highest specific capacitance of $132 \mathrm{~F} / \mathrm{g}$, and the specific capacitance remained above $90 \%$ at a high current density of $3 \mathrm{~A} / \mathrm{g}$. It was found that the high specific capacitance could be attributed to the increased micro-pore volume of ACs with pore sizes from 1 to $2 \mathrm{~nm}$, and the high power density could be attributed to the increased meso-pore volume.
\end{abstract}

Key words: activated carbon, pitch, electric double-layer capacitor, electrochemical properties

\section{Introduction}

The electric double-layer capacitor (EDLC) is an energy storage device that is superior to batteries in power density and life cycle. An EDLC stores electric energy by the adsorption-desorption of ions formed at an electric double layer between an electrode and electrolyte. Since the electrochemical performance of the EDLC changes dramatically depending on the electrode material and electrolyte, the choice of electrode material is very important [1-3].

For best performance, EDLC electrode materials should have a large specific surface area (SSA) and electrochemical stability to store lots of ions. For these reasons, porous carbon materials such as activated carbon (AC) have been widely used as the active material for EDLC electrodes. Although various ACs made of coal, coconut, timber, plant seed, etc. have been used as raw electrode materials [4-8], coal tar pitch (CTP) has been of interest as a precursor for EDLC electrode material because the AC produced from it has high a SSA and high activation yield. There have been many studies about the activation of CTP, CTP derived meso-carbon microbeads, and needle cokes [9-16].

Pore size distribution (PSD) can be changed by the activation conditions and has a huge effect on the capacity of an EDLC. Although it is conventionally known that the optimum pore sizes of an AC should be in the range of 3-5 nm (that is, meso-pores) to have a high 
capacitance EDLC $[17,18]$, recent studies have proposed that micro-pores are more important than meso-pores for the capacity of an EDLC $[19,20]$. It has been suggested that the development of pore volumes in the range of 1-2 $\mathrm{nm}$ is important and governs the capacitance of EDLC with an organic electrolyte [19]. Chomila and coworkers have also reported that specific capacitance was heavily dependent on the micro-PSD and demonstrated that an anomalous increase in specific capacitance at pore sizes less than $1 \mathrm{~nm}$ was due to the decrease of distance between electrolyte ions and electrode materials [20].

Although previous works have mostly focused on the effect of activation conditions on the surface area and PSD, there are only a few reports about adjusting pore size based on the structure of pitch precursor [21]. Petroleum pitch (PP) can also be used as a precursor for AC. Its molecular weight distribution is normally broader and its aromaticity is lower than CTP, and there is a difference in pore formation between the two types of ACs made from CTP and PP. It was suggested that this difference was due to the large amount of compounds with low molecular weight left in PP [22]. Petrova et al. [16] found that the chemical composition of CTP precursor by means of furfural addition significantly affected the physicochemical properties of the obtained AC, such as surface area, pore structure, electrical resistance, and oxygen-containing groups on the surface. Increased furfural content facilitated the formation of a solid product characterized by high oxygen content, and the solid product was more reactive towards activation, resulting in micro-porous carbons with large surface areas.

In this study, CTP was chemically activated with $\mathrm{KOH}$ at different activation temperatures and times to prepare various ACs with proper PSDs. The obtained AC materials were applied as EDLC electrodes with an organic electrolyte, and their electrochemical performance was investigated. The relationship between PSD and specific capacitance was demonstrated, to provide better information on the proper pore size for high capacitance EDLC. Mixtures of CTP and PP with different compositions were also activated to prepare ACs with improved EDLC performance. Since the CTP and PP had different chemical compositions, we tried to investigate the effect of $\mathrm{CTP} / \mathrm{PP}$ ratio on the pore structure and properties of the obtained AC. The obtained ACs were then fully characterized and investigated as an EDLC electrode.

\section{Experimental}

\subsection{Materials}

A commercial CTP provided by OCI Co., Ltd. was used as the raw material for the $\mathrm{AC}$. The $\mathrm{CTP}$, having a softening point of $292^{\circ} \mathrm{C}$, was stabilized at $300^{\circ} \mathrm{C}$ for $2 \mathrm{~h}$ under air in a tube furnace. A PP having a softening point of $205^{\circ} \mathrm{C}$ was provided by GS Caltex Co. The stabilized CTP, and mixtures of stabilized CTP and as-received PP were activated to prepare various ACs. Fourier-transform infrared (FT-IR) spectra of the CTP and PP were obtained using a Fourier transform infrared spectrophotometer (DRS-800, Shimazu Co.). The detailed information for the CTP and PP is shown in Table 1 and Fig. 1. Potassium hydroxide (KOH, Daejung Chem. \& Metals Co., Ltd., 85\%) was used as the activation agent and $\mathrm{N}_{2}$ gas (JC gas, 99.99\%) was flowed during $\mathrm{KOH}$ activation of the CTP and PP. The electrodes were prepared by mixing AC, Super-P, and poly vinylidene fluoride (PVDF, power, Aldrich) dissolved in 1-methyl2-pyrrolidone (NMP, 99.5\%, Sam Chun Pure Chem. Co., Ltd.). Coin type EDLC cells were assembled using polypropylene (PP) as a separator and $1 \mathrm{M}$ tetraethylammonium tetrafluoroborate in acetonitrile $\left(\mathrm{TEABF}_{4} / \mathrm{ACN}\right)$ as an electrolyte.

\subsection{Manufacture of AC}

Various ACs with proper PSDs were prepared by $\mathrm{KOH}$ activation of the stabilized CTPs at activation temperatures in the range of $700^{\circ} \mathrm{C}-1000^{\circ} \mathrm{C}$ for $1-3 \mathrm{~h}$ of activation time under $\mathrm{N}_{2}$ flow. The optimal mass ratio of $\mathrm{KOH}$ powder to CTP was selected to be 4:1. Various mixtures of CTP and PP at ratios of 10:0-1:1 were also activated to prepare ACs with different properties. The ACs obtained from the stabilized CTP and the mixtures of stabilized CTP and as-received PP were thoroughly washed with distilled water three times and dried at $110^{\circ} \mathrm{C}$ in an oven for 1 day.

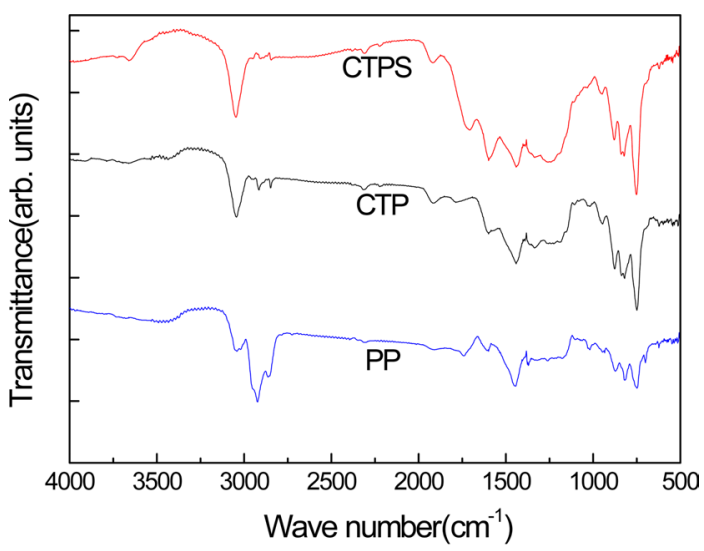

\begin{tabular}{cccc}
\hline Sample & CTP & CTPS & PP \\
\hline I $_{\text {aromaticity }}$ & 0.95 & 0.95 & 0.27 \\
\hline
\end{tabular}

Fig. 1. Fourier-transform infrared spectra of coal tar pitch (CTP), stabilized coal tar pitch (CTPS), and petroleum pitch (PP).

Table 1. Properties of CTP and PP

\begin{tabular}{|c|c|c|c|c|c|c|c|c|}
\hline \multirow{2}{*}{ Sample } & \multirow{2}{*}{$\begin{array}{l}\text { Softening point } \\
\left({ }^{\circ} \mathrm{C}\right)\end{array}$} & \multirow{2}{*}{ TI (\%) } & \multirow{2}{*}{ QI (\%) } & \multicolumn{4}{|c|}{$\mathrm{C}$} & \multirow{2}{*}{$\mathrm{C} / \mathrm{H}$ ratio } \\
\hline & & & & $\mathrm{C}$ & $\mathrm{H}$ & $\mathrm{N}$ & S & \\
\hline CTP & 292 & 68 & 33 & 93.5 & 3.78 & 1.04 & 0.32 & 2.06 \\
\hline PP & 205 & 7.8 & 1.4 & 94.0 & 5.95 & - & - & 1.32 \\
\hline
\end{tabular}

CTP: coal tar pitch, PP: petroleum pitch, TI: toluene insoluble, QI: quinoline insoluble. 
Table 2. Properties of activated carbons prepared from CTP at different activation conditions

\begin{tabular}{cccccccc} 
Sample & $\begin{array}{l}\text { Activation } \\
\text { conditions }\end{array}$ & $\begin{array}{c}\text { Yield } \\
(\%)\end{array}$ & SSA $\left(\mathrm{m}^{2} / \mathrm{g}\right)$ & $\mathrm{V}_{\text {micro }}\left(\mathrm{cm}^{3} / \mathrm{g}\right)$ & $\mathrm{V}_{\text {meso }}\left(\mathrm{cm}^{3} / \mathrm{g}\right)$ & $\mathrm{d}_{\text {ave }}(\mathrm{nm})$ & $\begin{array}{c}\text { Capacitance } \\
(\mathrm{F} / \mathrm{g})\end{array}$ \\
\hline $\mathrm{CTP}-81$ & $800^{\circ} \mathrm{C} 1 \mathrm{~h}$ & 58 & 2470 & 0.56 & 0.43 & 1.98 & 89 \\
$\mathrm{CTP}-82$ & $800^{\circ} \mathrm{C} 2 \mathrm{~h}$ & 55 & 2988 & 1.27 & 0.48 & 2.06 & 106 \\
$\mathrm{CTP}-83$ & $800^{\circ} \mathrm{C} \mathrm{3} \mathrm{h}$ & 50 & 2830 & 1.30 & 0.48 & 2.14 & 113 \\
$\mathrm{CTP}-84$ & $800^{\circ} \mathrm{C} 4 \mathrm{~h}$ & 55 & 3081 & 1.43 & 0.68 & 2.20 & 118 \\
$\mathrm{CTP}-73$ & $700^{\circ} \mathrm{C} \mathrm{3} \mathrm{h}$ & 56 & 2036 & 0.85 & 0.21 & 1.94 & 71 \\
$\mathrm{CTP}-93$ & $900^{\circ} \mathrm{C} 3 \mathrm{~h}$ & 43 & 3004 & 1.55 & 0.83 & 2.36 & 122 \\
$\mathrm{CTP}-103$ & $1000^{\circ} \mathrm{C} \mathrm{3} \mathrm{h}$ & 47 & 2618 & 0.97 & 0.87 & 2.54 & 92 \\
\hline
\end{tabular}

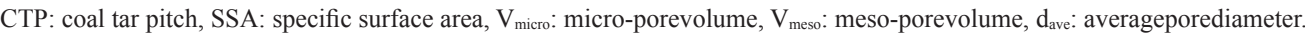

\subsection{Characterization and electrochemical performance of AC}

Pore structures of the obtained ACs were characterized by $\mathrm{N}_{2}$ adsorption/desorption measurements using an ASAP 2010 (Micromeritics) instrument. SSAs of the ACs were calculated by the Brunauer-Emmett-Teller (BET) method. The micro-pore analysis method (MP method) and the Barret-Joyner-Hallender (BJH) method were used to obtain the PSD of ACs. The crystallizability of pristine CTP, stabilized CTP, and activated CTP was determined by X-ray diffraction (XRD) measurements (Shimadzu, XRD-7000) using a $\mathrm{Cu}-\mathrm{K} \alpha$ radiation $(\lambda=1.54056 \AA)$ operated at $40 \mathrm{kV}$ and $30 \mathrm{~mA}$.

Electrodes were prepared by mixing AC, Super-P, and PVDF at a mass ratio of 8:1:1. PVDF and Super-P were used as a binder and a conductive additive, respectively. Coin-type EDLC cells were fabricated using two symmetrical carbon electrodes. The electrodes were punched into small disks of $18 \mathrm{~mm}$ diameter and placed into the coin cells. A $19 \mathrm{~mm}$ diameter separator soaked with electrolyte solution was placed between these electrodes. The coin cells were filled with $\mathrm{TEABF}_{4} / \mathrm{ACN}$ electrolyte inside an argon filled glove box [23]. Finally, the coin cell was sealed using a coin cell crimper. The specific capacitances of the electrodes were measured by a charge-discharge tester (WBCS-3000 Battery Charge/Discharge Cycler, WonA Tech Co., Ltd.). The tests were performed in the voltage range of $0-2.7 \mathrm{~V}$ at a constant current of $1 \mathrm{~A} / \mathrm{g}$. Cyclic voltammetry measurements $(\mathrm{CV}$, Potentiostat/Galvanostat Model $273 \mathrm{~A}$, EG\&G) were carried out at potential scan rates of 10 and 100 $\mathrm{mV} / \mathrm{s}$. Electrochemical impedance spectroscopy (EIS, Nova, Metrohm Autolab) measurements were performed in the frequency range of $0.01 \mathrm{~Hz}-100 \mathrm{kHz}$ at open circuit potential with an AC perturbation of $5 \mathrm{mV}$ [24].

\section{Results and Discussion}

\subsection{Characterizations of the raw pitches}

The properties of the CTP and PP are listed in Table 1. Although the softening point and $\mathrm{C} / \mathrm{H}$ ratio of the $\mathrm{CTP}$ were higher than those of PP, the differences in their solubility in toluene and quinoline were even more obvious. The huge difference in solubility between two pitches could be explained by the higher content of aromatic compounds in CTP. To analyze their aromaticity and chemical structure, FT-IR spectra of the two types of pitches are presented in Fig. 1. Some functional groups of CTP and PP were observed to be aromatic $(3050,1161,1505,1052$, $872,811,750$, and $\left.438 \mathrm{~cm}^{-1}\right)$ and aliphatic $(2955,2920,2855$, and $1450 \mathrm{~cm}^{-1}$ ) groups. Specifically, we can see the existence of aromatic C-H stretch at $3050 \mathrm{~cm}^{-1}$ and the stretching of aromatic $\mathrm{C}=\mathrm{C}$ at $1611-1470 \mathrm{~cm}^{-1}$ [25-28]. Compared to the PP, the CTP and stabilized CTPS had noticeable increases of absorption at $3050 \mathrm{~cm}^{-1}$ and decreases of absorption at $2920 \mathrm{~cm}^{-1}$ but there were no significant differences between CTP and CTPS. The aromaticity index of various pitches was calculated by Eq. (1) made by Guillén et al. [25].

$$
\mathrm{I}_{\text {aromaticity }}=\mathrm{Abs}_{3050}\left(\mathrm{Abs}_{3050}+\mathrm{Abs}_{2920}\right)
$$

The aromaticities of CTP, CTPS and PP were evaluated to be $0.95,0.95$, and 0.27 respectively.

\subsection{Optimization of activation conditions for CTP}

The properties of the ACs prepared from CTP by $\mathrm{KOH}$ activation at $700^{\circ} \mathrm{C}-1000^{\circ} \mathrm{C}$ for $1-4 \mathrm{~h}$ are summarized in Table 2 . With increasing activation time at $800^{\circ} \mathrm{C}$, the specific capacitance of the AC increased, up to $4 \mathrm{~h}$. As the activation temperature was varied from $700^{\circ} \mathrm{C}$ to $1000^{\circ} \mathrm{C}$ for $3 \mathrm{~h}$ of activation time, the specific capacitance of the $\mathrm{AC}$ increased up to $900^{\circ} \mathrm{C}$ but it reduced with further increase of activation temperature. Thus, the activation treatment of $900^{\circ} \mathrm{C}$ for $3 \mathrm{~h}$ was selected as having the optimal activation conditions, and provided the largest specific capacitance of $122 \mathrm{~F} / \mathrm{g}$. The specific capacitance was calculated by a charge-discharge test in a two-electrode system using Eq. (2).

$$
\mathrm{C}=4 \times(I \times \Delta t) /(2 m / \Delta V)
$$

Here $\mathrm{C}$ is the specific capacitance, I the discharge current, $\Delta t$ the discharge time, $\mathrm{m}$ the mass of the electrode, and $\Delta V$ the alteration of voltage. 

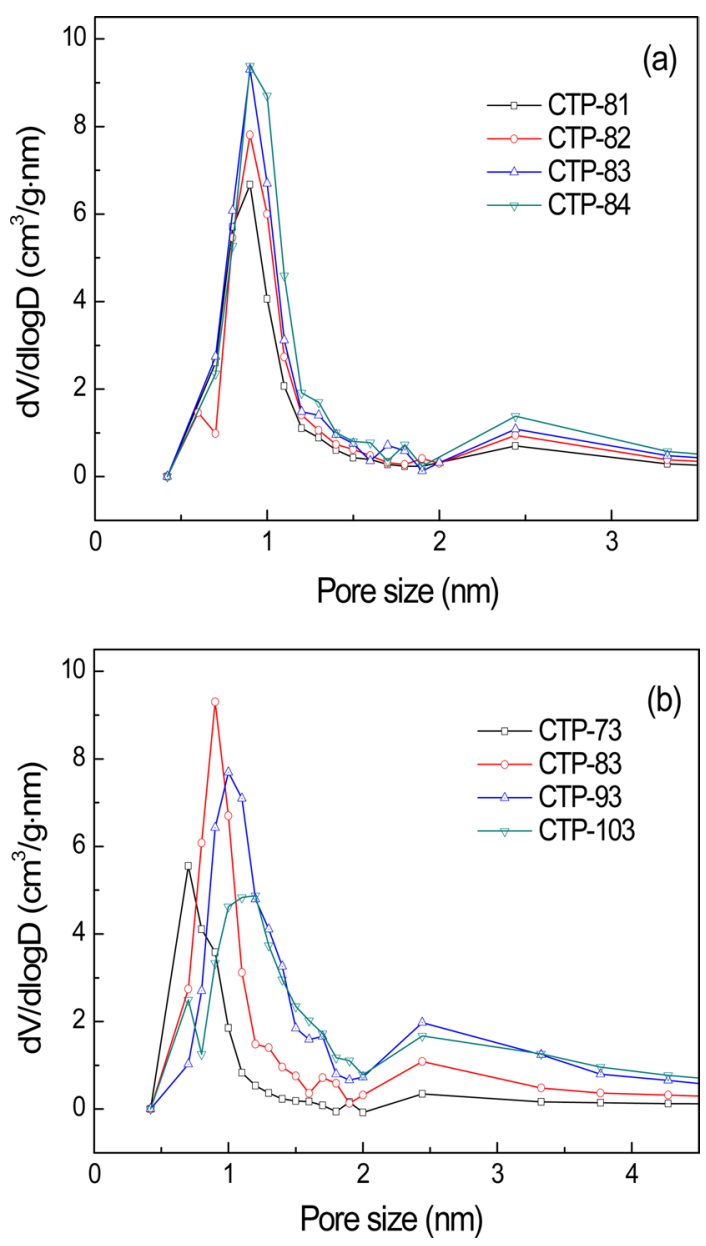

Fig. 2. Pore size distributions of activated carbons from coal tar pitch (CTP) activated (a) at $800^{\circ} \mathrm{C}$ for $1-4 \mathrm{~h}$ and (b) at $700^{\circ} \mathrm{C}-1000^{\circ} \mathrm{C}$ for $3 \mathrm{~h}$.

Fig. 2 shows the PSD of ACs fabricated from CTPs activated at $800^{\circ} \mathrm{C}$ for $1-4 \mathrm{~h}$ (a) and at $700^{\circ} \mathrm{C}-1000^{\circ} \mathrm{C}$ for 3 $\mathrm{h}$ (b). It can be seen that with increasing activation time at $800^{\circ} \mathrm{C}$, the pore volumes of ACs with pore sizes from 1 to $2 \mathrm{~nm}$ tend to increase. The specific capacitance of the ACs also increased with increasing activation time as shown in Table 2. As the activation temperature increased from $700^{\circ} \mathrm{C}$ to $1000^{\circ} \mathrm{C}$ with $3 \mathrm{~h}$ of activation time, the pore volumes of the $\mathrm{AC}$ with pore sizes from 1 to $2 \mathrm{~nm}$ increased up to $900^{\circ} \mathrm{C}$ but it reduced at $1000^{\circ} \mathrm{C}$ activation. Since the specific capacitance of the electrodes and the PSD of the ACs exhibited a similar trend according to the activation conditions, it was demonstrated that the pore volume of ACs with pore sizes from 1 to $2 \mathrm{~nm}$ was suitable for high electrode performance in the organic electrolyte EDLC system.

To confirm the change of crystal structure based on the AC preparation process, XRD profiles of as-received CTP, stabilized CTPS, and CTP activated at $900^{\circ} \mathrm{C}$ for $3 \mathrm{~h}$ (CTP-93) are presented in Fig. 3. Both the CTP and CTPS had a diffraction peak (002) of graphite at $2 \theta=25^{\circ}$, but it disappeared for CTP93, indicating the disintegration of the graphitic crystal structure and the formation of a well-developed pore-structure through the $\mathrm{KOH}$ activation of CTP [9].

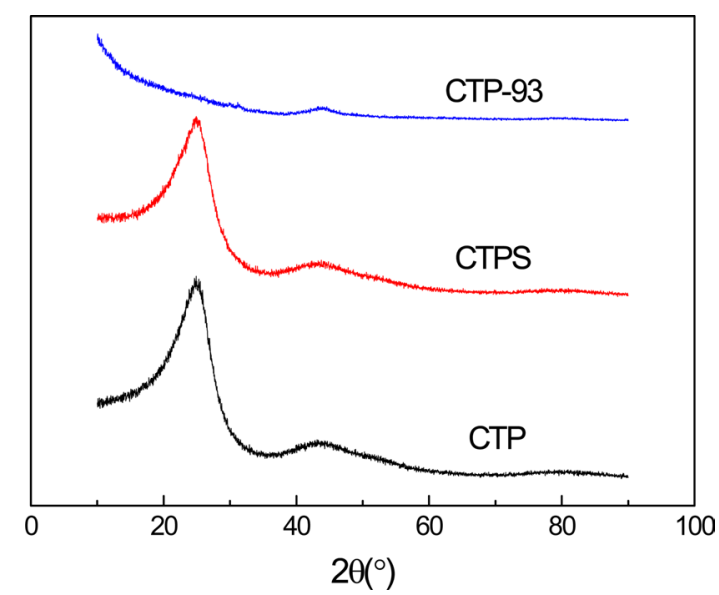

Fig. 3. X-ray diffraction patterns of coal tar pitch (CTP), stabilized coal tar pitch (CTPS), and activated CTP at $900^{\circ} \mathrm{C}$ for $3 \mathrm{~h}$ (CTP-93).

\subsection{Properties of a mixture of CTP and PP}

In order to examine the differences in physical and electrochemical properties of ACs according to the chemical composition of their precursor pitches, various mixtures of CTP and PP were activated. Table 3 presents the properties of ACs prepared from different mixtures of CTP and PP with activation conditions of $900^{\circ} \mathrm{C}$ and $3 \mathrm{~h}$. For comparison, the property of a well- known commercial activated carbon, MSP-20 (Kansai Coke \& Chemicals Co., Japan), is also shown. In general, the pitch-based ACs had higher SSAs and pore volumes than those of MSP-20.

Compared to the CTP-93, the AC from CTP-PP11 had a little bit increased SSA and similar micro- and meso-pore volumes. For the ACs with increased CTP contents such as CTP-PP41 and CTP-PP61, the SSA and micro-pore volume decreased a little bit, but meso-pore volumes and average pore diameter increased. The AC prepared from CTP-PP61 had the highest pore volume and average pore diameter. Fig. 4 shows the PSDs of MSP-20, and the ACs from various mixtures of CTP and PP. In the micro-pore analysis of Fig. 4a, MSP-20 had large PSD in the range of $0.5-1 \mathrm{~nm}$, while the pitch-based ACs had large PSD in the range of 1-2 $\mathrm{nm}$. For the meso-pore analysis of Fig. 4b, the difference of PSD between MSP-20 and the pitch-based ACs is more obvious. This large PSD could help to achieve outstanding electrochemical performance at high current rates.

Although the PSDs of ACs prepared from various mixtures of CTP and PP were very much similar to each other, the pore volume less than $1 \mathrm{~nm}$ declined but the pore volume sizing from 1 to $2 \mathrm{~nm}$ as well as the meso-pore volume increased with the increased CTP contents in the pitch mixtures, showing a maximum with CTP-PP61.

As shown in Table 1 and Fig. 1, the chemical composition of PP is quite different from that of CTP. Compared with CTP, the molecular weight distribution of PP is broader and the aromaticity is lower. Since PP has a larger amount of compounds with low molecular weight and a lower content of aromatic hydrocarbon, PP might have some harmful effect on the formation of graphite crystals during the heat treatment of the activation process. The less graphitic carbon prepared with a high content 
Table 3. Properties of commercial AC (MSP-20), and ACs prepared from different mixtures CTP and PP at activation conditions of $900^{\circ} \mathrm{C}$ and $3 \mathrm{~h}$

\begin{tabular}{ccccccc} 
Sample & CTP:PP & Yield $(\%)$ & SSA $\left(\mathrm{m}^{2} / \mathrm{g}\right)$ & $\mathrm{V}_{\text {micro }}\left(\mathrm{cm}^{3} / \mathrm{g}\right)$ & $\mathrm{V}_{\text {meso }}\left(\mathrm{cm}^{3} / \mathrm{g}\right)$ & $\mathrm{d}_{\text {ave }}(\mathrm{nm})$ \\
\hline MSP-20 & - & - & 2277 & 0.96 & 0.11 & 1.76 \\
CTP-93 & $10: 0$ & 43 & 3004 & 1.55 & 0.83 & 2.36 \\
CTP-PP61 & $6: 1$ & 40 & 2967 & 1.51 & 0.99 & 2.54 \\
CTP-PP41 & $4: 1$ & 46 & 3006 & 1.53 & 0.92 & 2.44 \\
CTP-PP11 & $1: 1$ & 43 & 3056 & 1.57 & 0.82 & 2.35 \\
\hline
\end{tabular}

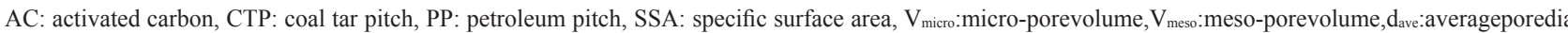
meter.
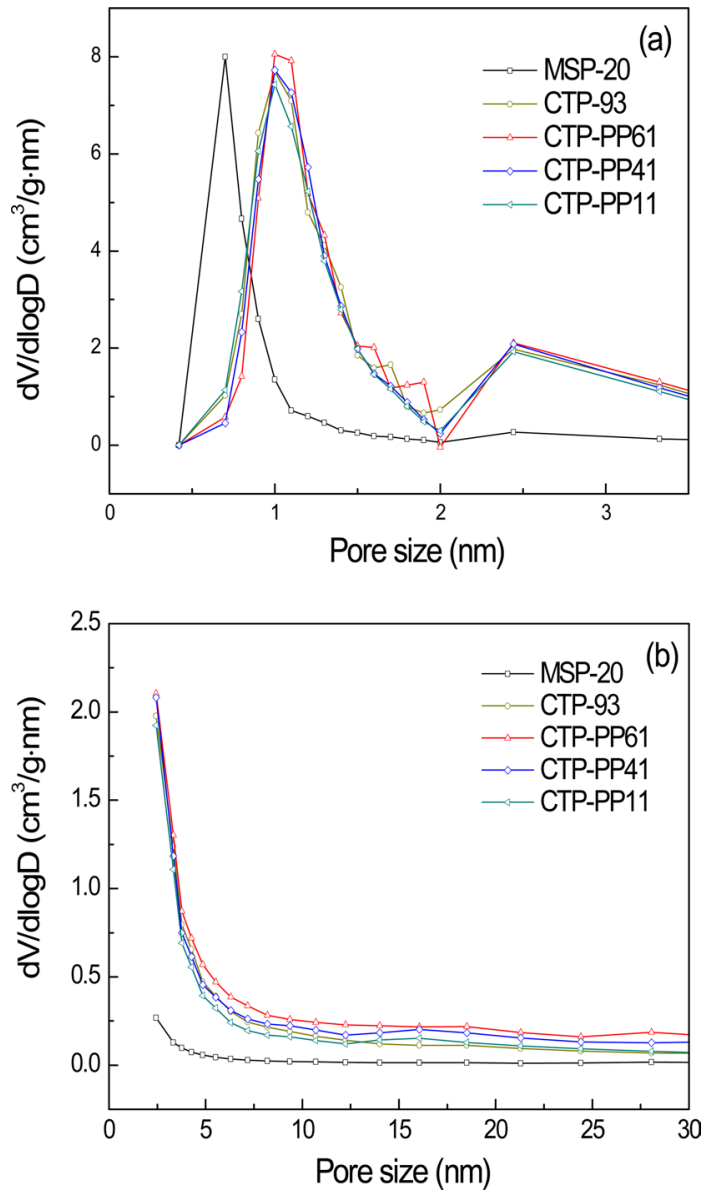

Fig. 4. Pore size distributions of commercial activated carbon (AC, MSP20), and ACs prepared from various mixtures of coal tar pitch (CTP) and petroleum pitch (PP): (a) micro-pore analysis and (b) meso-pore analysis.

of PP would be more reactive towards activation by $\mathrm{KOH}$, generating the more developed pore-structure.

However, the control of porosity during $\mathrm{KOH}$ activation was not easy with just the PP precursor. Thus, a mixture of PP and CTP was used to provide structural deviation in the precursor mixture. Activation means the removal of less graphitic carbons by selective oxidation. So, the deviation in the graphitic structure would allow easier control of porosity depending on the extent of activation. A more favorable structural condition for the

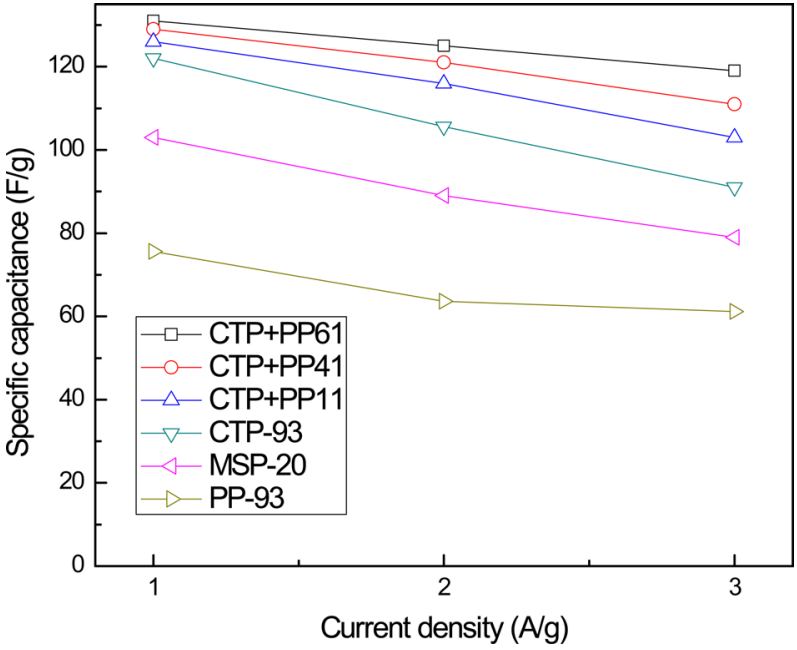

Fig. 5. Specific capacitances of commercial activated carbon (AC, MSP20), and ACs prepared from various mixtures of coal tar pitch (CTP) and petroleum pitch (PP) as a function of current density.

proper pore-size distribution could be obtained with a mixture of CTP and PP. Since the pore volume of ACs with pore sizes from 1 to $2 \mathrm{~nm}$ was suitable for high electrode performance in our EDLC system, the AC prepared from CTP-PP61 could be expected to exhibit the highest electrochemical performance.

Fig. 5 shows the specific capacitance of MSP-20, and the ACs prepared from various mixtures of CTP and PP, measured by a charge-discharge test in the voltage range of $0-2.7 \mathrm{~V}$ and plotted as a function of current density. The specific capacitance of ACs prepared from the mixtures of CTP and PP was better than that from CTP only, and MSP-20. Although the specific capacitance of the AC electrodes fabricated from CTP only, and from mixtures of CTP and PP, was not significantly different at a current density of $1 \mathrm{~A} / \mathrm{g}$, the $\mathrm{AC}$ electrodes from CTP and PP mixtures showed outstanding specific capacitance at higher current rates. In particular, CTP-PP61 had the highest specific capacitance of $132 \mathrm{~F} / \mathrm{g}$ at a current density of $1 \mathrm{~A} / \mathrm{g}$, and the specific capacitance remained above $90 \%$ at a high current density of $3 \mathrm{~A} / \mathrm{g}$. It was demonstrated that the high specific capacitance could be attributed to the increased micro-pore volume of ACs with pore sizes from 1 to $2 \mathrm{~nm}$, and the high power density could be attributed to the increased meso-pore volume.

EIS analysis was conducted to explore the internal resistances 


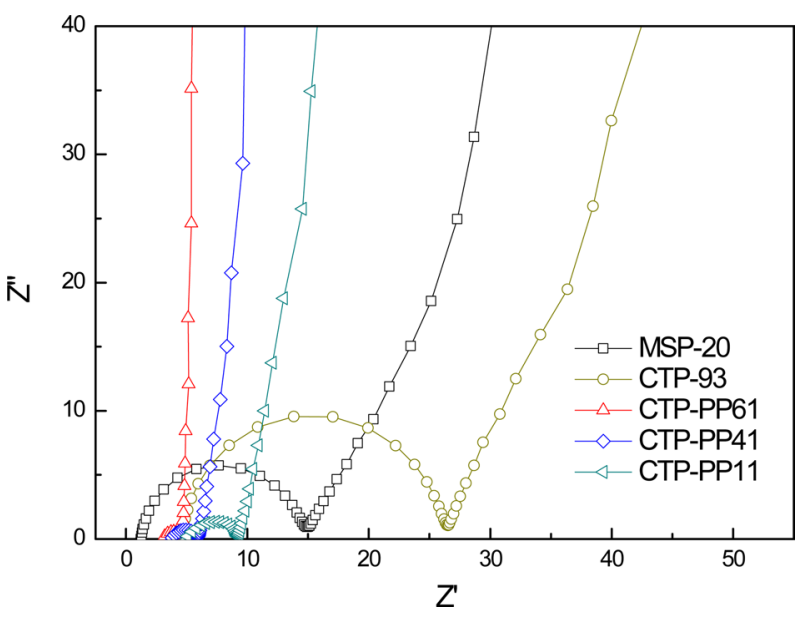

Fig. 6. Electrochemical impedance spectroscopy of electric doublelayer capacitor using activated carbon (AC, MSP-20), and ACs prepared from various mixtures of coal tar pitch (CTP) and petroleum pitch (PP).

\begin{tabular}{|c|c|c|c|}
\hline & $\mathrm{R}_{\mathrm{s}}$ & $\mathrm{R}_{\mathrm{c}}$ & $\mathrm{R}_{\text {int }}$ \\
\hline MSP-20 & 1.27 & 14.9 & 22.0 \\
\hline СТР-93 & 4.66 & 26.5 & 31.0 \\
\hline СТP-PР61 & 3.19 & 1.34 & 5.20 \\
\hline СТP-PР41 & 3.80 & 2.07 & 8.00 \\
\hline СТР-PР11 & 5.08 & 4.16 & 13.0 \\
\hline
\end{tabular}

AC: activated carbon, CTP: coal tar pitch, PP: petroleum pitch, Rs:bulksolut ionresistanceoftheelectrolyte, $\mathrm{R}_{\mathrm{c}}$ : internalcontactresistanceoftheelectrode, $\mathrm{R}_{\text {int }}$ : internalresistanceofthecell.

of EDLCs using various ACs as electrode material. In an EDLC system, the response to a sinusoidal potential $\mathrm{E}$ will be a sinusoidal current I at the same frequency with a shift in phase. The resulting impedance $\mathrm{Z}$ is the following complex number.

$$
Z=E / I=Z_{0} \exp (j \theta)=Z_{0}(\cos \varphi+j \sin \varphi)=Z^{\prime}+j Z^{\prime \prime}
$$

Fig. 6 shows the EIS of different AC electrodes prepared from the mixtures of CTP and PP, and CTP-93 in the frequency range of $0.01 \mathrm{~Hz}-100 \mathrm{kHz}$. The Nyquist graphs not only present the resistance value but also reflect the dynamic process needed to form electric double layers. The Nyquist plots for various samples were similar to each other. They were composed of a semicircle region at high frequencies, a sloping linear region at medium frequencies, and a nearly vertical line at low frequencies [29].

In a Nyquist plot, there are two resistances, solution resistance $\left(R_{s}\right)$ and internal contact resistance of the electrode $\left(R_{c}\right)$. $R_{s}$ comes from the bulk solution resistance depending on the electrolyte conductivity and the separator material. $R_{c}$ can be separated into two components: the electronic and the ionic resistances. The electronic resistance includes the intrinsic elec-
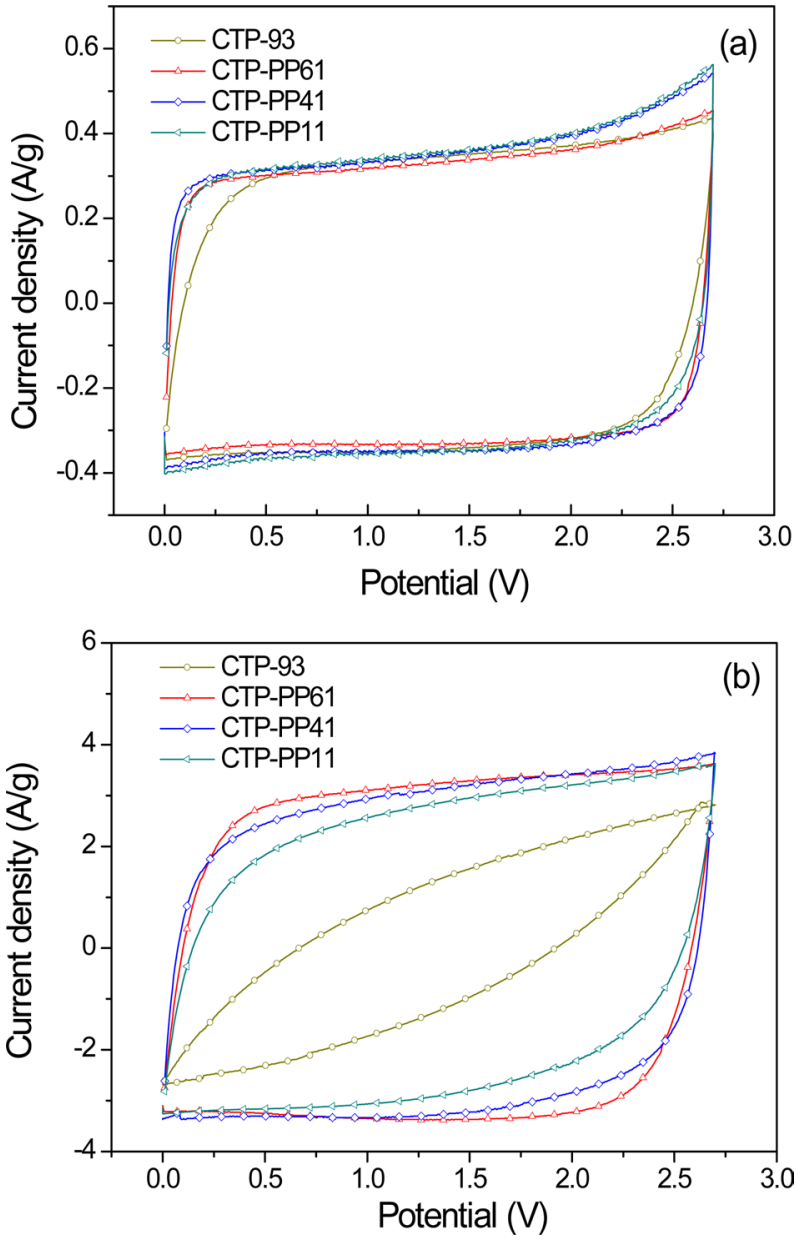

Fig. 7. Cyclic voltammograms of activated carbon electrodes prepared from various mixtures of coal tar pitch (CTP) and petroleum pitch (PP) at a scan rate of (a) $10 \mathrm{mV} / \mathrm{s}$ and (b) $100 \mathrm{mV} / \mathrm{s}$.

tronic conductivity of the carbon particles, the electronic contact between particles, and the contact between the active layer and the current collector. The ionic resistance is the electrolyte ionic resistance inside the pores of the electrode depending on the electrolyte conductivity and pore structure of the electrode materials. $R_{s}$ and $R_{c}$ can be determined by the beginning and terminal points of a semicircle in the Nyquist plot. The internal resistance of the cell, $\mathrm{R}_{\mathrm{int}}$, is estimated from the intersection between the straight section of the Nyquist plot and the $\mathrm{X}$-axis [30]. The impedance data for the various samples are listed in Table 4.

The semicircle terminal points for AC electrodes prepared from the mixtures of CTP and PP were much lower than those for CTP-93 and MSP-20 due to their well-developed pore structures including the larger meso-pore volumes. With increasing CTP content, $R_{s}$ decreased, showing a minimum of $1.34 \Omega$ with CTP-PP61. The CTP-PP61 sample also had a minimum $\mathrm{R}_{\text {int }}$ of $5.20 \Omega$.

$\mathrm{CVs}$ of AC electrodes prepared from the various mixtures of CTP and PP are presented in Fig. 7. As shown in Fig. 7a, CV curves for all five samples showed a rectangular, symmetric, and reversible shape in the voltage range of $0-2.7$ at a scan rate of 
$10 \mathrm{mV} / \mathrm{s}$. As the scan rate increased to a high scan rate of 100 $\mathrm{mV} / \mathrm{s}$, the $\mathrm{CV}$ curve for CTP-93 changed into a rugby ball shape and the specific capacitance decreased dramatically. However, the shape of the CV curve and their specific capacitance for the mixtures of CTP and PP remained at a high scan rate of 100 $\mathrm{mV} / \mathrm{s}$. The excellent capacitance behavior of pitch-based ACs at high scan rates indicates that their equivalent series resistance was very low.

\section{Conclusions}

Various ACs were prepared by $\mathrm{KOH}$ activation of CTP and from mixtures of CTP and PP for application as the electrodes of EDLCs. For ACs prepared from CTP only, the optimal activation conditions were determined to be a $\mathrm{CTP} / \mathrm{KOH}$ ratio of $1: 4$, activation temperature of $900^{\circ} \mathrm{C}$, and activation time of $3 \mathrm{~h}$. The obtained ACs showed increased PSD in the range of 1 to $2 \mathrm{~nm}$ and the specific capacitance of $122 \mathrm{~F} / \mathrm{g}$ in a two-electrode system with an organic electrolyte.

In order to improve the performance of the EDLC electrode, mixtures of CTP and PP were activated at the optimal activation conditions previously determined for CTP. By introducing a small amount of PP into the CTP, the obtained AC electrodes showed improved specific capacitance as well as outstanding power density. It was demonstrated that the high specific capacitance can be attributed to the increased micro-pore volume of ACs with pore sizes from 1 to $2 \mathrm{~nm}$, and the high power density can be attributed to the increased meso-pore volume.

\section{Acknowledgements}

This work was supported by the World-Class 300 Project (Development of high rate capacity over $9.0 \mathrm{Ah} \mathrm{Li} / \mathrm{SOCl}_{2}$ wound cell \& highly safe 32 Volts Pack battery, high voltage $(6 \mathrm{~V} / 24 \mathrm{~V})$ super-capacitor module \& $10 \mathrm{kWh}$ Zn-Ni Flow Battery) funded by the Small and Medium Business Administration of Korea (SMBA).

\section{References}

[1] Sharma P, Bhatti TS. A review on electrochemical double-layer capacitors. Energy Convers Manage, 51, 2901 (2010). http://dx.doi. org/10.1016/j.enconman.2010.06.031.

[2] Pandolfo AG, Hollenkamp AF. Carbon properties and their role in supercapacitors. J Power Sources, 157, 11 (2006). http://dx.doi. org/10.1016/j.jpowsour.2006.02.065.

[3] Endo M, Takeda T, Kim YJ, Koshiba K, Ishii K. High power electric double layer capacitor (EDLC's): from operating principle to pore size control in advanced activated carbons. Carbon Sci, 1, 117 (2001).

[4] Wu J, Hong IP, Park SM, Lee SY, Kim MS. Electrochemical properties of EDLC electrodes prepared by acid and heat treatment of commercial activated carbons. Carbon Lett, 9, 137 (2008).

[5] Galinski M, Babel K, Jurewicz K. Performance of an electrochemical double layer capacitor based on coconut shell active material and ionic liquid as an electrolyte. J Power Sources, 228, 83 (2013) http://dx.doi.org/10.1016/j.jpowsour.2012.11.048.

[6] Kim SG, Yim JB, Kim KM, Lee YW, Kim MS, Kang AS. Performance of electric double layer capacitor of rice hull activated carbon electrode. Hwahak Konghak, 39, 424 (2001).

[7] Mitani S, Lee SI, Saito K, Korai Y, Mochida I. Contrast structure and EDLC performances of activated spherical carbons with medium and large surface areas. Electrochim Acta, 51, 5487 (2006) http://dx.doi.org/10.1016/j.electacta.2006.02.040.

[8] Elmouwahidi A, Zapata-Benabithe Z, Carrasco-Marín F, Moreno-Castilla C. Activated carbons from $\mathrm{KOH}$-activation of argan (Argania spinosa) seed shells as supercapacitor electrodes. Bioresour Technol, 111, 185 (2012). http://dx.doi.org/10.1016/j. biortech.2012.02.010.

[9] Huh JH, Seo MK, Kim HY, Kim IJ, Park SJ. Influence of KOH activation on electrochemical performance of coal tar pitch-based activated carbons for supercapacitor. Polymer (Korea), 36, 756 (2012). http://dx.doi.org/10.7317/pk.2012.36.6.756.

[10] Torchala K, Kierzek K, Machnikowski J. Capacitance behavior of $\mathrm{KOH}$ activated mesocarbon microbeads in different aqueous electrolytes. Electrochim Acta, 86, 260 (2012). http://dx.doi. org/10.1016/j.electacta.2012.07.062.

[11] Li F, Chi W, Shen Z, Wu Y, Liu Y, Liu H. Activation of mesocarbon microbeads with different textures and their application for supercapacitor. Fuel Process Technol, 91, 17 (2010). http://dx.doi. org/10.1016/j.fuproc.2009.08.020.

[12] Huang CC, Chen YZ. Electrochemical performance of supercapacitors with $\mathrm{KOH}$ activated mesophase carbon microbead electrodes. J Taiwan Inst Chem Eng, 44, 611 (2013). http://dx.doi. org/10.1016/j.jtice.2012.12.017.

[13] Zheng C, Gao J, Yoshio M, Qi L, Wang H. Non-porous activated mesophase carbon microbeads as a negative electrode material for asymmetric electrochemical capacitors. J Power Sources, 231, 29 (2013). http://dx.doi.org/10.1016/j.jpowsour.2012.12.041

[14] Roh KC, Park JB, Lee CT, Park CW. Study on synthesis of low surface area activated carbons using multi-step activation for use in electric double layer capacitor. J Ind Eng Chem, 14, 247 (2008) http://dx.doi.org/10.1016/j.jiec.2007.08.012.

[15] Mitani S, Lee SI, Saito K, Yoon SH, Korai Y, Mochida I. Activation of coal tar derived needle coke with $\mathrm{K}_{2} \mathrm{CO}_{3}$ into an active carbon of low surface area and its performance as unique electrode of electric double-layer capacitor. Carbon, 43, 2960 (2005). http://dx.doi. org/10.1016/j.carbon.2005.05.047

[16] Petrova B, Tsyntsarski B, Budinova T, Petrov N, Ania CO, Parra JB, Mladenov M, Tzvetkov P. Synthesis of nanoporous carbons from mixtures of coal tar pitch and furfural and their application as electrode materials. Fuel Process Technol, 91, 1710 (2010). http:// dx.doi.org/10.1016/j.fuproc.2010.07.008.

[17] Mayer ST, Pekala RW, Kaschmitter JL. The aerocapacitor: an electrochemical double-layer energy-storage device. J Electrochem Soc, 140, 446 (1993). http://dx.doi.org/10.1149/1.2221066.

[18] An KH, Kim WS, Park YS, Choi YC, Lee SM, Chung DC, Bae DJ, Lim SC, Lee YH. Supercapacitors using single-walled carbon nanotube electrodes. Adv Mater, 13, 497 (2001). http:// dx.doi.org/10.1002/1521-4095(200104)13:7<497::AIDADMA497>3.0.CO;2- $\mathrm{H}$

[19] Endo M, Kim YJ, Ohta H, Ishii K, Inoue T, Hayashi T, Nishimura Y, Maeda T, Dresselhaus MS. Morphology and organic EDLC applications of chemically activated AR-resin-based carbons. Carbon, 40, 2613 (2002). http://dx.doi.org/10.1016/S0008-6223(02)00191- 
4

[20] Chmiola J, Yushin G, Gogotsi Y, Portet C, Simon P, Taberna PL. Anomalous increase in carbon capacitance at pore sizes less than 1 nanometer. Science, 313, 1760 (2006). http://dx.doi.org/10.1126/ science.1132195.

[21] Heo GY, Park SJ. Effects of structure of heat-treated pitch precursors on electrochemical properties of pitch-based activated carbons. Powder Technol, 239, 94 (2013). http://dx.doi.org/10.1016/j. powtec.2013.01.049.

[22] Daguerre E, Guillot A, Stoeckli F. Activated carbons prepared from thermally and chemically treated petroleum and coal tar pitches. Carbon, 39, 1279 (2001). http://dx.doi.org/10.1016/S00086223(00)00251-7.

[23] Kwon SH, Lee E, Kim BS, Kim SG, Lee BJ, Kim MS, Jung JC. Activated carbon aerogel as electrode material for coin-type EDLC cell in organic electrolyte. Curr Appl Phys, 14, 603 (2014). http:// dx.doi.org/10.1016/j.cap.2014.02.010.

[24] Lee YJ, Park HW, Kim GP, Yi J, Song IK. Supercapacitive electrochemical performance of graphene-containing carbon aerogel prepared using polyethyleneimine-modified graphene oxide. Curr Appl Phys, 13, 945 (2013). http://dx.doi.org/10.1016/j. cap.2013.02.005.
[25] Guillén MD, Iglesias MJ, Domínguez A, Blanco CG. Fourier transform infrared study of coal tar pitches. Fuel, 74, 1595 (1995). http://dx.doi.org/10.1016/0016-2361(95)00139-V.

[26] Akezuma M, Okuzawa K, Esumi K, Meguro K, Honda H. Physicochemical properties of quinoline-soluble and quinolineinsoluble mesophases. Carbon, 25, 517 (1987). http://dx.doi. org/10.1016/0008-6223(87)90192-8.

[27] Ōtani S. Mechanism of the carbonization of MP carbon fiber at the low temperature range. Carbon, 5, 219 (1967). http://dx.doi. org/10.1016/0008-6223(67)90003-6.

[28] Yoo MJ, Ko HJ, Lim YS, Kim MS. Modification of isotropic coaltar pitch by acid treatments for carbon fiber melt-spinning. Carbon Lett, 15, 247 (2014). http://dx.doi.org/10.5714/CL.2014.15.4.247.

[29] Choi WS, Shim WG, Ryu DW, Hwang MJ, Moon H. Effect of ball milling on electrochemical characteristics of walnut shellbased carbon electrodes for EDLCs. Microporous Mesoporous Mater, 155, 274 (2012). http://dx.doi.org/10.1016/j.micromeso.2012.01.006.

[30] Lei C, Markoulidis F, Ashitaka Z, Lekakou C. Reduction of porous carbon/Al contact resistance for an electric double-layer capacitor (EDLC). Electrochim Acta, 92, 183 (2013). http://dx.doi. org/10.1016/j.electacta.2012.12.092. 